\title{
Research International Journal of Energy \& Environmental Sciences
}

\section{Short Communication}

\section{Water Revolution}

\section{Oleg Khalidullin*}

Academician of Kazakh National University, Kazakhstan

*Address for Correspondence: Oleg Khalidullin, Academician of Kazakh National University, Kazakhstan. Tel: +87770550099; Email: 7115215@mail.ru

Received: 27 April 2020; Accepted: 15 June 2020; Published: 16 June 2020

Citation of this article: Khalidullin O (2020) Water Revolution. Rea Int Journal of Energy Environmental sci. 1 ( 1 ): 001 -004. DOI: $10.37179 /$ rijees.000001.

Copyright: (C) 2020 Khalidullin O. This is an open access article distributed under the Creative Commons Attribution License, which permits unrestricted use, distribution, and reproduction in any medium, provided the original work is properly cited.

The natural purpose of water on the surface of the earth is to supply all things on earth

With minerals, salts, and organic matter. Precipitating, water dissolves the substances of the soil and presents it to plants and animals.

She almost does not stand without work and movement. Inside organisms and plants, water is repeatedly transformed into various states and comes out by transpiration, expiration, and other secretions.

Evaporated into the atmosphere creates the main component of precipitation. A continuous flow of water into the atmosphere and back forms a hydrological cycle. Little-known processes are taking place in the clouds, which you can only guess and make assumptions about.

Water molecules, in the atmosphere, in a state of gas, when accumulated in certain concentrations, temperatures, structural and property ratios, continuously alter their phase state. In each of them, processes of mixing, the interaction of molecules of various waters, occur. Under certain specific conditions, water droplets or crystals returns to the ground.

Are the molecules raised in the clouds the same? Do they have the same structure? Does the quality of the gas phase and its volumes, properties depend on the conditions of transition from the liquid and solid phases from the soil surface? Can evaporation from the surface of the ocean from transpiration of a plant be the same? Do atmospheric transformations depend on the quality of water vapor? What are the states and properties of the molecular structures of water in the atmosphere, what is happening above our heads, what determines the quality of the cloud cover? Reflections and the search for answers to such questions lead to interesting studies and assumptions in explaining the nature of precipitation and climate change.
With increasing volumes, the clouds thicken, increase in thickness and area, block the flow of solar radiation. In this state, they can hang for several hours to several days, and nobody knows what happens there.

However, you can notice that the clouds move along certain specific routes and precipitation falls at approximately the same places, in certain volumes, at the certain time. These signs show what has happened for millions of years in processes related to water and its circuit. Life on earth depends on precipitation and its volume.

The regularity of precipitation in the same places creates various humid environments in which various plants and animals appear. From this, various habitats were created with the corresponding species of plants and animals in certain zones and the tropics? steppes, forests formed.

The distribution and stability of all areas on the planet shows that the clouds follow in accordance with their own law's unknown to us. It was also established that water and its structure have not been studied, have many of their secrets, for example, their properties depend on the place, external influences on water, that gasoline cannot burn without water: https://oum.video/videos/velikaya-tayna-vody/

And these laws developed and improved before the development of civilization. A man, saw a workshop in nature, began to use its components to increase his comfort.

The words of the great classic from the novel "Fathers and Sons" A. Turgenev "Nature is not a temple, but a workshop and the person in it is a worker" has become a strategy in relation to nature, especially to water.

Mankind has begun to influence this workshop in a wide variety of ways. Destruction of forests, ploughing of lands, watering by reservoirs, filling up areas with garbage and ore landfills, burning, burning fuel in the air, using water in technological and municipal processes. 
All these types of work are united by a single and most important consequence of environmental impact - a change in the quality of water vapor. No information was found on the quality, volume, and speed of the most common types of fumes.

The main links in the movement and transformation of water in the cycle are:

- Evaporation of water from oceans, open reservoirs, from all land - soil, from snow and ice cover, from transpiration of plants, from the secretions and of all living things.

- Consolidation, concentration, mixing, interaction of many molecules of various vapors, create a variety of atmospheric conditions with their temperatures, pressures, and electromagnetic fields.

- Chemical and physical processes in the atmosphere, because of which, water molecules pass into a gaseous, liquid droplet and solid state, lead to the formation of clouds.

- Precipitation of liquid and solid phases of different volumes and in different places with the manifestation of various activities in the form of rains, snowfalls, cyclones, hurricanes.

- Precipitation on land settles on glaciers, forms stream, replenishes rivers, goes underground, Sand flows into the seas and oceans.

- Moving masses of water along rivers and underground channels dissolve minerals and decaying organic matter.

- A significant part of these resources enters the roots of plants, nourish animals. Part of the water with salts remains in organisms and plants for long periods, for example, in growing bones and wood. But the main moisture in the body does not stay, its most part regularly and gradually comes out with secretions, exhalation, transpiration. These organic vapors have their own distinctive natural properties.

- Combining with the vapors from the oceans, organic waste creates its own local substance above each area, forming special clouds.

This feature is a local replace as phenomenon in atmospheric transformations and created life on the planet. The volumes and frequency of precipitation have stabilized over millions of years, and a comfortable distribution of moisture has appeared for everything on the planet.

A third of the entire planet's surface is land. The common notion that the seas and oceans, which cover $2 / 3$ of the entire planet, therefore evaporate most of the water, is a myth. It was found that, if we summarize the transpiration surface of the vegetation of all land, then the entire area of evaporation from land becomes equal to the area of the entire surface of the oceans and seas - https://vuzlit. ru/984043/transpiratsiya\#597.

This fact should introduce new ideas and concepts about the ratio of fumes. And the role of evaporation in sedimentation. The quality, quantity and rate of evaporation are essential components of atmospheric transformations.

On each hectare of fertile soil, 20 tons of underground living creatures live, each creature of which consumes water, takes salt from it, converts it into various elements of its body and releases waste from its life into the atmosphere. This is the most important link in the water cycle. Water is processed, purified from minerals, and acquires a structure with its individual properties of each essence, each plant in each form. Gas-liquid emissions from a living creature and plants are not just correct the $\mathrm{H} 2 \mathrm{O}$ molecules.

This molecular structure with its properties, for example, odours, statement conflicting. It differs significantly from a water molecule raised from the surface of the water or from asphalt and a drying washed item.

In nature, this feature has its purpose. It is necessary for orientation and search for partners, victims, preservation, and life of procreation. The differences are used in modern medicine - a person's health status is diagnosed by the quality of his waste - expiration, other secretions. A variety of emissions is also necessary for further programming of the actions and the path of moisture in the atmosphere.

The appearance of man and the increase in water consumption by him went beyond the limits of natural necessity. A man enslaved water and began to use it not only for drinking but to suit many of his comfort requirements. Water began to perform unusual functions, which were not, prescribed by nature, on such a scale. We turned water into a means of transferring heat, energy, transport, a purifier, a solvent, a cooler, a product. They began to compress, boil, sell, dissolve various substances in it, wash it with everything and anything.

The volumes of water enslavement have grown so much that they have become commensurate with natural fumes. Quantity goes into quality - clouds of a new kind began to change the water cycle itself. The rationale for this may be the following information: https://vyvoz.org/: “... More than 75\% of the Earth's land area has already been degraded, and by 2050 this figure may exceed $90 \%$. Land degradation is a process that degrades soil quality due to aspects such as land misuse, agriculture and pasture, urban or industrial targets and so on."

To this should be added that water, falling onto such soil, does not find its natural consumer and, bypassing the transformation link, evaporates back into the atmosphere, virtually unchanged. The process of the circuit, shortened by an entire link, on three quarters of the entire land remained unnoticed by a person. But not by nature.

There is evidence that we take 23 Cubic meter or about $10 \%$ of all fresh water from nature for our needs and technological processes. Each drop of such water evaporates immediately, upon heating, after use, after discharge into the sewer and sludge in treatment tanks. Natural reservoirs, for example, the Aral Sea, began to disappear:

https://zen.yandex.ru/media/lubopitnij_facti/aralskaiakatastrofa-prichiny-i-posledstviia-gibeli-odnogo-iz-samyhkrupnyh-vodoemov-5a79aa219d5cb3539bae62dd

The volumes and speed of such unnatural vapors, let us call them artificial, were beyond the scope of attention. $10 \%$ of all fresh water on land is a fairly tangible part of nature, which is growing every day, with every new power plant, new technology. There is no comparative analysis of the volumes and rates of evaporation in the pre-industrial era and at present. Without citing scientific research, based on sound reasoning, we can conclude that evaporation from boiling water, asphalt, drying after washing, sewage, cooling in cooling towers in nature did not exist in principle. These are all artificial fumes. 
Under the normal load of the CHP, one-unit cools over 10,000 cubic meters of liquid per hour. Artificial evaporations from cooling towers begin to prevail over organic ones.

As a new quality of moisture accumulates in the atmosphere, the volume and speed of the circuit of artificial vapors cause unknown transformations to atmosphere. However, we all observe and suffer from changes in the patterns of precipitation. Artificial vapors "prevail over evaporation from biota".

The substance of the cloud cover has changed, qualities, volumes, speeds, and travel routes of movement of clouds. The result of this is an excess of rainfall in some places with catastrophic floods, droughts, and forest fires in others.

The mechanism of water distribution over areas has broken. Clouds burdened by artificial vapors do not reach the mountain and polar glaciers, spilling precipitation along the way, replenishing the level of the oceans. Therefore, it is logical to assume B or hypothesis that artificial fumes distorted the processes of precipitation in the atmosphere, the water cycle itself and began to change the climate.

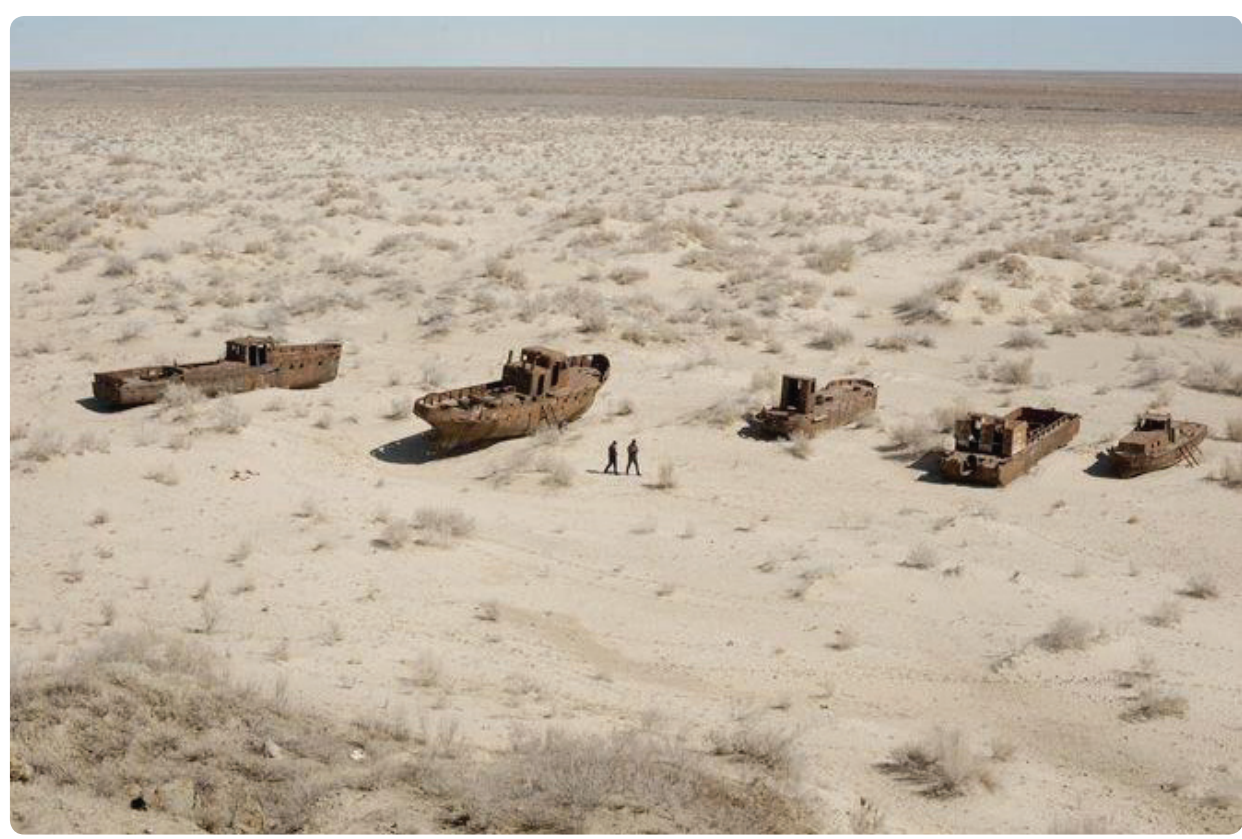

Figure 1: Shows a photo of the former bottom of the Aral Sea in Kazakhstan. Its waters went into an ugly irrigation of cotton fields along irrigation canals laid in the sands and most of this water evaporated from the surface of these irrigation canals and saturated the soil.

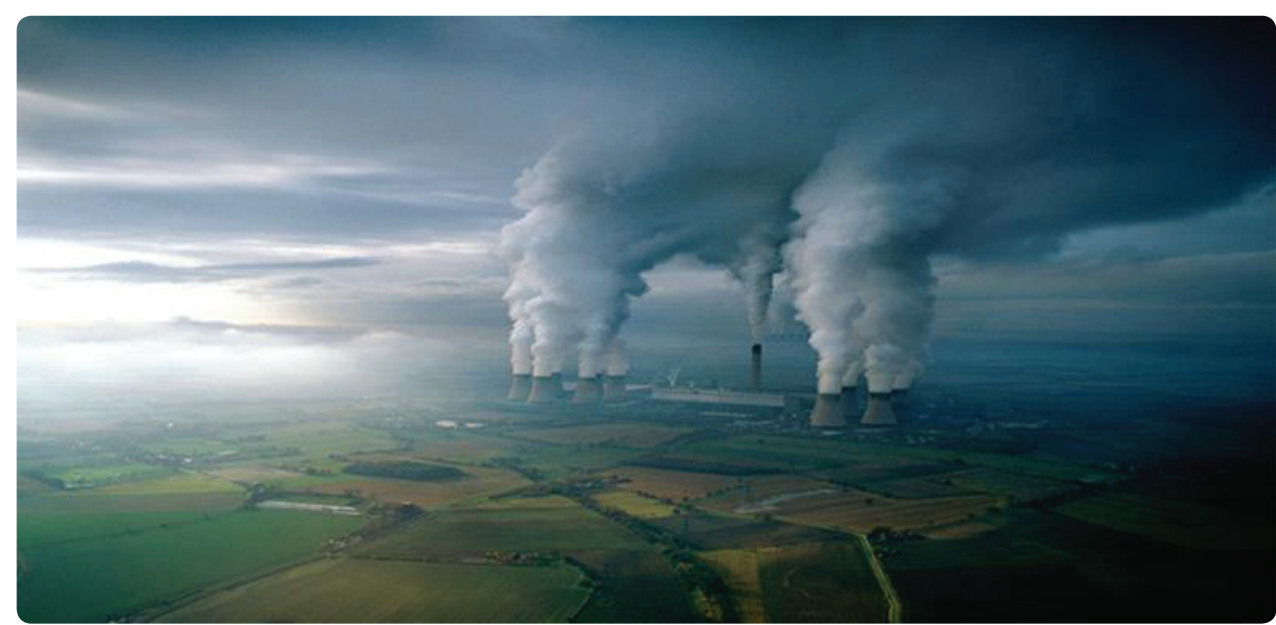

Figure 2: Shows a photo of the cooling tower: https://acs-nnov.ru/gradirni-tec.html.

Under the normal load of the CHP, one-unit cools over 10,000 cubic meters of liquid per hour. Artificial evaporations from cooling towers begin to prevail over organic ones. 
It should be borne in mind that the quality and quantity of output vapors and emissions is purely individual for each of the billions of consumers. The number and species of plants and animals characterize their habitat, and, apparently, in their own way affect the substance of the clouds and atmospheric transformations.

All biota fumes are structures that form their individual composition in the atmosphere above each geographical point. In the process of atmospheric transformations, many factors are involved. The quality, volume and frequency of gas-liquid formation It is quite possible that these water substances in the clouds are the basis of precipitation and climate, participate in determining the time, place and amount of precipitation and cause an immediate reaction to their changes.

We do not see the differences between the vapors, but we feel their effects on ourselves - changes in the graphs, geography, and volumes of precipitation, we see the death of biota and the increase in natural disasters.

Perhaps it is not too late to stop these imbalances. For this, returning water to its natural functions and freeing it from slavery "would suffice". Many man-made impacts on nature, such as burning fuel with atmospheric moisture, deforestation, ploughing fields, mining of minerals and non-metallic minerals, construction of reservoirs, cities and roads - each such intervention in nature makes a significant contribution to the increase in water in the atmosphere.

It is necessary to reduce water consumption "in all non-essential purposes, and", in all technological processes. Now the processes of artificial evaporation of water are increasing with menacing acceleration. New cities and constructions are being built, rivers and canals are turning dry, millions of different methods and devices of artificial evaporation are invented and manufactured - irons and humidifiers, devices for washing, washing, drying, hardening, cooling.

If we want to leave our descendants a well-maintained planet, we must stop the uncontrolled abuse of water. Each type of water consumption should be reviewed from the perspective of abusive utilization natural principles. It should not be mere rhetoric of advice, appeals

and warnings like closing faucets, but a single planetary strategy with a radical revision of the principles of water use.

The prioritization in the UN report does not see and does not solve such a problem.

https://e.mail.ru/attach/15861731121030017273/0\%3B0/?folderid $=500013 \& x$-email $=7115215 \% 40$ mail.ru

Presentation of the UN World Water Resources Report March 22 Paris / Geneva, March 22. Climate change will have a negative impact on the availability, quality and quantity of water resources needed to meet basic human needs, thereby undermining the enjoyment of basic rights to safe drinking water and sanitation for billions of people.

This is the main message of the United Nations World Water Development Report.

The assertion that climate negatively affects water resources - this is akin to cart in front of the horse - the cause and effect are reversed. Water forms a climate, but now climate has a negative impact on water. It was our impact on water resources that changed the water cycle and, as a result, climate change began. Every person should have the right to safe drinking water, but water should be given the priority to fulfill their natural functions.

Humanity can affect water resources, and water resources define the climate. "Fundamental rights to safe drinking water" are the same right as any living creature and nature does not take it away, but now, the addition of abusive uses of water is a mistake of mankind. The enslavement of water is not provided for by nature. Man, as a child of nature, can have rights only to drink water, but not to other needs. It is necessary to rebuild this thesis on "Fundamental water rights in nature" to save the lives of billions of people and biota.

It is not the climate that affects the availability, quality, and quantity of water resources, but the unnatural utility of water resources affects the vapors, and the vapors affect the climate. The satisfaction of basic human needs should be limited to natural need for only drinking. Everything else should be reduced to a minimum. Of course, not immediately, but we must begin to move in this direction. We must begin to move very intensively. or else natural disaster will increase in frequency and volume over every geographical location.

It is necessary to radically change the attitude to water at all levels of life and protect life of the entire population of the planet. The basis of the new concept should be such areas.

- Reduction of artificial water areas.

- Transition to shallow plowing, drip irrigation.

- Stopping deforestation.

- Reduction of landfills and ore landfills.

- A complete review of the use of water in production and in everyday life.

- Complete revision of sewer systems except for centralization: https://www.actascientific.com/ASMI/pdf/ASMI-02-0228.pdf,

https://opastonline.com/wp-content/uploads/2019/10/sewerage -and-climate-jmsro-19.pdf 